DATA DE

RECEPCIÓN:

$15 / 09 / 2020$

DATA DE

ACEPTACIÓN:

$15 / 11 / 2020$

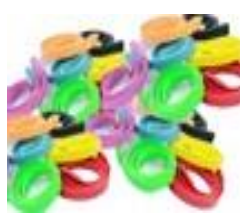

\section{LER OS CLÁSICOS: ALICIA EN LINGUA GALEGA}

\author{
LEER LOS CLÁSICOS: ALICIA EN LENGUA GALLEGA
}

READ THE CLASSICS: ALICE IN GALICIAN LANGUAGE

\author{
Isabel Mociño-González \\ Universidade de Vigo \\ https://orcid.org/0000-0001-6516-168X \\ imocino@uvigo.es \\ Blanca-Ana Roig Rechou \\ Universidade de Santiago de Compostela \\ https://orcid.org/0000-0003-0326-4311 \\ blanca.roig@usc.es
}

Resumo: Neste traballo faise un percorrido polas traducións, versións e adaptacións que, dende a década dos anos oitenta e ata a actualidade, se fixeron á lingua galega da obra de Lewis Carroll, Alice's Adventures in Wonderland. Despois dun breve repaso aos condicionamentos socio-político-culturais que sufriu o sistema literario infantil e xuvenil galego, explícanse algunhas das principais vías seguidas pola tradución á lingua galega, con especial atención ao tratamento dos clásicos universais. Por último, revísase con máis detalle as características das edicións publicadas en lingua galega deste clásico universal.

Palabras chave: tradución, clásico, Carroll, lingua galega.

Resumen: En este trabajo se realiza un recorrido por las traducciones, versiones y adaptaciones que, desde la década de los años ochenta y hasta la actualidad, se han realizado de la obra de Lewis Carroll, Alice's Adventures in Wonderland. Después de un breve repaso a los condicionantes socio-político-culturales sufridos por el sistema literario infantil y juvenil gallego, se explican algunas de las principales vías seguidas por la traducción a la lengua gallega, con especial atención al tratamiento de los clásicos universales. Por último, se revisa con más detalle las características de las ediciones publicadas en lengua gallega de este clásico universal.

Palabras clave: traducción, clásico, Carroll, lengua gallega.

Abstract: In this work we take a look at the translations, versions and adaptations that have been made of Lewis Carroll's work, Alice's Adventures in Wonderland, from the 1980s to the present day. After a brief review of the sociopolitical-cultural conditions suffered by the Galician children's and young adult literary system, some of the main paths followed by translation into Galician are explained, with special attention to the treatment of universal classics. Finally, the characteristics of the Galician language editions of this universal classic are reviewed in more detail. Keywords: translation, classic book, Carroll, Galician language. 


\section{Introdución}

Alice's Adventures in Wonderland, a obra máis universal de Lewis Carroll (Charles Lutwidge Dodgon, Daresbury, Cheshire, 1832-Guildford, 1898), foi traducida por primeira vez á lingua galega a inicios dos anos oitenta do século XX, coincidindo co período de consolidación do sistema literario infantil e xuvenil. Dende entón coñeceu diferentes traducións, adaptacións e versións nesta lingua meta, polo que é de interese observar o momento no que se produciu a transferencia, a forma en como se incorporou a este sistema literario e a fortuna da obra dentro del, pois estas estratexias poden explicar algunha das vías seguidas na incorporación de modelos e novas opcións ao repertorio literario, así como a súa contribución ao reforzo, lexitimación e autosuficiencia deste fronte ao sistema central, o castelán.

Non esquezamos que a transferencia é un dos recursos dos sistemas emerxentes ${ }^{1}$ para acumular unha reserva importante de elementos que contribúan á súa estabilidade, a chamada lei de proliferación (Even-Zohar, 1978: 43; 2008), dado que a través das obras estranxeiras se van introducindo características que antes non existían no sistema de chegada e asumindo funcións ausentes nesa cultura, de aí que a literatura traducida veña cubrir a necesidade dunha literatura nova que ten que poñer a súa lingua a funcionar na maior cantidade posíbel de xéneros literarios para facela útil para os seus usuarios (Even-Zohar, 1996: 61). É por iso que, tal como apunta Antón Figueroa (2003: 64), o estudo deste intercambio interliterario e a súa incidencia na historia literaria de cada cultura presupón instrumentos metodolóxicos que explican a complexa rede de relacións entre o estado do sistema doméstico e a esencia da actividade da transferencia, ao tempo que desvela as relacións entre o poder e o mercado. Por outra parte, tal como sinala Gideon Toury (1995), a tradución está suxeita a limitacións nas que non só inflúen as características do texto ou das linguas coas que se traballa, senón que os factores socioculturais afectan ás estratexias adoptadas polos tradutores e, como consecuencia, ao resultado final.

Abordar a evolución da tradución no sistema literario infantil e xuvenil galego implica referirse a unhas circunstancias histórico-socio-político-económicas pouco favorábeis (Roig, 2015; Luna Alonso, Fernández Rodríguez, Galanes Santos e Montero Küpper, 2015) que determinaron a carencia de instrumentos de lexitimación e arrastraron durante tempo uns condicionamentos propios² $^{2}$ Aínda así, a tradución de Literatura Infantil e Xuvenil (a partir de agora LIX) á lingua galega representa o 70\% do volume da importación entre 1981 e 2011, tal como revela a base de datos da

\footnotetext{
${ }^{1}$ Como era o galego na década dos anos oitenta do século XX cando se comezaron a transvasar as obras de Lewis Carroll.

${ }^{2}$ Entre eles a propia condición da LIX que foi considerada unha ferramenta para a educación e formación pedagóxica da infancia pero non como un fenómeno literario (Shavit, 2003: 11).
} 
Biblioteca da Tradución Galega (BITRAGA), o que evidencia a súa relevancia dentro do sistema literario.

\section{Tradución e LIX galega: condicionantes e primeiros pasos}

Como se ten posto de manifesto en numerosos traballos críticos sobre as traducións ao sistema literario infantil e xuvenil galego (Domínguez, 2008a, 2008b, 2008c, 2012a: 121-136; 2012b: 113-127; Mociño e Agrelo, 2008; Agrelo e Mociño, 2010; Fernández Rodríguez 2010: 93 107; Bendoiro, 2012: 39-51; Roig Rechou, 2015; Luna Alonso, Fernández Rodríguez, Galanes Santos e Montero Küpper, 2015; Luna, 2017), foi na década dos anos oitenta do século XX cando a tradución adquiriu máis pulo ${ }^{3}$ e contribuíu ao asentamento e posterior consolidación deste sistema literario, que comezou a contar cunha produción regular de obras pensadas para os máis novos.

Isto concorda co apuntado por Blanca-Ana Roig Rechou (2005: 141), quen afirma que despois dunha etapa de "transición” na década dos anos sesenta, o sistema literario infantil e xuvenil pasou por un "afianzamento" na década dos anos setenta e comezou a "consolidación” na dos oitenta, momento no que a lingua galega foi adquirindo unha dimensión social e pública cada vez maior, amparada na Constitución Española e nas leis dela derivadas, fundamentalmente a Lei Orgánica 1/1981, de 6 de abril, pola que se aprobou o Estatuto de Autonomía de Galicia (BOE 101, de 28 de abril de 1981); e, sobre todo, a promulgación da Lei de Normalización Lingüística (3/1983, de 15 de xuño, Parlamento de Galicia, DOG, 14 de xullo de 1983), que oficializaron a lingua galega nos ámbitos administrativos e educativos, aínda que as condicións sociopolíticas mantiñan un mercado no que os resultados eran froito máis dun compromiso intelectual e político ca puramente empresarial.

Á vista da evolución da tradución á lingua galega dende outros sistemas literarios que se pode seguir en Roig (1995-2018) ou ata 2008 en Roig, Domínguez e Mociño (2008), as principais vías seguidas pola importación ao sistema literario infantil e xuvenil, tal como se recolle con detalle en Roig (2015) e Mociño (2015), son as seguintes:

- as coedicións, recurso co que se iniciou a importación de LIX en Galicia e que permitiu

\footnotetext{
${ }^{3}$ Non se esqueza que foi precisamente no ano 1982 cando apareceu por primeira vez a LIX galega representada no Certamen Internacional Hans Christian Andersen coa obra colectiva Contos pra nenos (1979), da Agrupación Cultural O Facho, publicada por Galaxia, onde se acolleron os relatos de Paco Martín "Sabeliña e os ratos", Xoán Babarro "Zoca zoqueira", María Victoria Moreno "O cataventos", Eliseo Alonso "O cabaliño que fuxira do curro" e Dora Vázquez "Cascabel, o cabaliño do circo". Tamén porque neste ano se iniciou a publicación de coleccións emblemáticas encargadas da incorporación de obras de autores clásicos da LIX universal á galega, como foi o caso de "Xabarín" posta en marcha por Edicións Xerais de Galicia.
} 
ás editoras ofrecer produtos cuxos custos non lle eran asumíbeis, aínda que resultaban imprescindíbeis para a formación do lectorado na lingua propia, a defensa da cultura e, sobre todo, para a normalización lingüística. Esta estratexia desembocou nunha complexa rede de relacións que deu como froito multiedicións de consorcios editoriais que publicaron, simultaneamente, obras para a primeira infancia en todas as linguas do estado, froito máis do interese por reducir gastos ca por unha verdadeira planificación (Domínguez, 2012: 132);

- as autotraducións, que proliferaron nas etapas iniciais de configuración do sistema literario, cuxos protagonistas foron autoras e autores que, condicionados por unhas circunstancias histórico-culturais marcadas pola ditadura, comezaran a escribir na lingua central pero que, posteriormente, arrastrados polos cambios sociais e as demandas de colectivos comprometidos coa cultura, verteron as súas obras á lingua galega para contribuír á normalización lingüística e literaria;

- as traducións de clásicos universais, como a obra que nos ocupa, que representan unha estratexia de carácter ideolóxico e político-literario, aínda que cuestionada para a autonomía da lingua meta se se prolonga no tempo (Galanes, 2010), a cal fornece o sistema cun corpus de títulos canónicos que teñen unha dobre función: a literaria e a cultural, ao exercer o corpus traducido un papel de reforzo de novos modelos literarios polo prestixio do sistema de orixe;

- e as traducións de autores contemporáneos, vía que representa o maior peso cuantitativo da produción traducida, a cal pasou de se centrar no intercambio entre sistemas do marco ibérico nos anos oitenta e noventa, a experimentar importantes cambios nos primeiros anos do o século XXI, entre outras razóns pola incorporación ao mercado de editoriais que adoptaron estratexias diferentes na importación de LIX, como Kalandraka, OQO Editora, Lata de Sal ou El Patito Editorial, entre outras moitas, contribuíndo á renovación do discurso e tamén dos formatos, aínda que o aumento anual de traducións non significa necesariamente o mesmo nivel de calidade literaria, que nalgúns casos é cuestionábel (Mociño, 2015).

É, polo tanto, na terceira das vías sinaladas, a da importación de clásicos universais, na que nos deteremos a seguir, para observar as principais características que presenta o sistema literario infantil e xuvenil na incorporación deste corpus, para posteriormente centrarnos na fortuna da obra de Carroll, Alicia no País das Marabillas, en lingua galega. 


\section{Os clásicos universais na LIX galega}

A tradución de autores considerados clásicos da literatura universal á lingua galega para o público infantil e xuvenil comezou na década dos anos setenta con O Principiño (Galaxia, 1972), de Antoine de Saint-Exupéry, realizada por Carlos Casares, que a trasladou dende a lingua de orixe, o francés. Esta primeira tradución supuxo o comezo dun proceso destinado a suplir o baleiro de obras canónicas no sistema de chegada e a afirmación dunha cultura minorizada (Galanes, 2014). Porén non foi ata a década seguinte cando comezou a ser máis regular a tradución de clásicos da literatura universal, que se incluíron en diferentes coleccións, xa infantís, xa xuvenís.

Un dos exemplos máis paradigmáticos é a colección "Xabarín", de Edicións Xerais de Galicia, que se centrou nos grandes clásicos universais, pois a editorial aspiraba a convertela nun referente para mozos e mediadores. Foi precisamente pensando nestes destinatarios que os seus responsábeis editoriais, conscientes do descoñecemento que rodeaba a LIX, engadiron nos volumes peritextos como introducións, biobibliografías, notas a pé de páxina... para situar autores e obras no seu contexto. Ademais, a colección lanzou obras inscritas en correntes temáticas pouco frecuentes até o momento no sistema galego (aventuras, misterio, ficción científica etc.), a través de solventes traducións (Mociño, 2010b: 46-47; Bendoiro, 2015; Roig, 2015), entre elas as das obras de Carroll, como veremos.

A incorporación destes textos traducidos considérase fundamental na fase filolóxica ou de acumulación de capital simbólico do sistema literario e no proceso de normalización lingüística ${ }^{4}$ (Lema, 2009: 128-129), unha vez que se supera a etapa de resistencia propia do sistema emerxente ao transvase cultural dentro do proceso de descolonización cultural ${ }^{5}$. Unha estratexia coa que se pretende consolidar unha corrente literaria formal, emerxente na década dos anos oitenta (Bendoiro, 2012: 44), que coincidiu co inicio dunha política de axudas á edición, creación literaria e tradución da Xunta de Galicia ${ }^{6}$, a cal non impulsou por iso unha planificación cultural, como se evidencia pola debilidade dalgúns xéneros (especialmente poesía e teatro) e a improvisación no terreo da tradución, feito que segue vixente na actualidade, ao seguir sen a planificación precisa para guiar o lectorado e o mediador cronoloxicamente polas obras consideradas canónicas.

\footnotetext{
${ }^{4}$ Aspecto que se recolle tamén entre as recomendacións para a planificación lingüística no Plan Xeral de Normalización da Lingua Galega (PXNLG) publicado en 2005.

${ }^{5}$ Que o profesor Anxo Tarrío Varela (1986: 399ss) observa no sistema literario galego en trazos como a expresión nun primeiro estadio en rexistro lírico, na predominancia do modo imperativo, propio dunha literatura de liberación colectiva, valoración do propio fronte á cultura do colonizador ou a creación de mitos compensadores cos que se valora o estadio autóctono propio anterior á colonización, que ben se poden aplicar tamén, con certas restricións, ao caso da Literatura Infantil e Xuvenil galega.

${ }^{6}$ Das que Silvia Montero Küpper (2013) se ocupa con detalle.
} 
Entre os aspectos máis salientábeis da tradución de clásicos universais á lingua galega cabe citar o feito de que conviven nunha mesma colección obras consideradas lecturas xuvenís con outras que na literatura fonte ou de orixe forman parte da literatura de adultos ou institucionalizada, situándose na denominada literatura de fronteira (Roig, 2008: 113) ou crossover fiction (Beckett, 2008), feito que non só se vai dar no sistema literario galego. Esta desviación probabelmente responda, nun primeiro momento, á necesidade de garantir un sector máis amplo de público lector, en parte debido á ampliación do período de escolarización obrigatoria e á necesidade de contar con lecturas acordes a idades con maior formación e intereses, o que propiciou a consolidación e auxe desas coleccións de fronteira, á vez que converteu a literatura xuvenil, como di Gemma Lluch (2009: 94), nun fenómeno editorial e mesmo sociolóxico. A isto cremos preciso engadir a falta de hábito lector na poboación adulta galega, que se inclina por acceder aos clásicos na lingua central, o castelán (Alonso, 2006: 91).

Por todo isto é de interese observar como evolucionaron as estratexias editoriais que, fundamentalmente a partir da primeira década do século XXI, renovaron moitas destas coleccións enchendo os paratextos de elementos subliminares e incluso facéndoos desaparecer cando acenan cara a un lectorado concreto ou indican as franxas de idade, aínda que sen renunciar a algunhas chiscadelas á cultura xuvenil. Por outra parte, tamén é preciso ter en conta que a inclusión dunha obra traducida nunha colección infantil ou xuvenil condiciona o tradutor/a, pois como confesan Xoán Manuel Garrido Vilariño e Ana Luna Alonso (1998: 189), o tradutor/a imaxina un destinatario ideal que, consciente ou inconscientemente, inflúe na súa toma de decisións, entre elas as propias obras que son traducidas (Luna, 2017).

\section{A obra de Lewis Carroll en lingua galega}

Os primeiros contactos da infancia galega coa obra de Lewis Carroll en lingua propia foi a través de adaptacións, concretamente a que en 1983 publicou Susaeta co título de Alicia no país das maravillas $^{7}$. Trátase dunha adaptación chea de erros (tanto conceptuais coma lingüísticos) que recrea a anécdota central da obra: o encontro de Alicia co coello branco e a entrada no mundo marabilloso. Esta primeira adaptación da obra de Carroll hai que situala no momento en que se aproba a Lei de Normalización Lingüística e editoras de ámbito nacional ven en Galicia un potencial nicho de mercado para os seus produtos traducidos a esta lingua, pois a versión en lingua castelá desta obra saíra publicada un ano antes, en 1982. Ademais, esta primeira adaptación responde a unha das catro

\footnotetext{
${ }^{7}$ Publicación que contou co apoio da Deputación Provincial de Lugo e foi distribuída por Distribuciones Souto.
} 
fontes que identifica Victoria Sotomayor (2005), a dos clásicos da literatura infantil, das que proceden na súa maior parte os textos adaptados, xunto cos contos populares, os clásicos da literatura xeral e as novelas de aventuras. Neles, o texto adaptado (hipertexto) é o resultado da transformación do hipotexto (texto orixinal) a través dunha simplificación, para facilitar a lectura dun público menos avezado do que orixinalmente prevé a obra.

A baixa calidade literaria e estética desta primeira aproximación á obra de Carroll foi seguida, un ano despois, en 1984, pola súa tradución íntegra en As aventuras de Alicia no País das Maravillas $^{8}$, que mereceu o Premio Nacional de Tradución do Ministerio de Cultura en 1985 e foi publicada inmediatamente na colección emblemática á que nos referimos, "Xabarín”. Neste caso preséntase unha tradución moi axustada ao orixinal, da man de Teresa Barro e Fernando PérezBarreiro, responsábeis tamén dunha esclarecedora introdución e abondosas notas que acompañan o texto. Na introdución comezan referíndose á consideración de clásico do relato, á súa referencialidade en todos os planos da sociedade inglesa (político, medios de comunicación, escolas, teatros e vida cotiá en xeral), o seu profundo alcance, a súa constante actualidade e novas dimensións, porque malia que

\footnotetext{
Alicia deu pé a tantas interpretacións: relixiosas, políticas, lóxico-matemáticas, psicoanalíticas. Todas con ánimo de dici-la última palabra. E sempre ficou algo máis, para outros explicadores. Como na Biblia, como en Shakespeare, como no amor, como na vida... (Carroll 1984: 8)
}

Seguen referíndose brevemente á personalidade de Carroll e ás hipóteses sobre os seus xogos de desdobramento Dodgson/Carroll, ás particulares circunstancias que marcaron a época vitoriana como un prolífico período, no que salienta a imaxinación creadora do autor e a orixinalidade de Alicia, dado que

\footnotetext{
Non hai nada igual antes nin despois dela. ¿A que xénero corresponde? Imposible situala. Fálase de "nonsense" ou absurdo, pero esa é unha cualificación que "Alicia" certamente posúe, máis que non a define como forma, non a estructura como producto artístico. O Ulises de Joyce é máis como unha novela que "Alicia" como un conto de fadas. E, deixando a cuestión da forma, o material imaxinativo non ten tampouco precedentes, nin a ausencia de moralexas. Tense insistido moito neste último contraste con toda a literatura infantil anterior e grande parte da seguinte (...). "Alicia” é unha grande “outra cousa” da literatura. (Carroll 1984: 12)
}

A seguir detéñense na xénese da obra e relatan a anécdota que lle deu orixe o 4 de xullo de 1862, para repasar tamén brevemente a produción posterior de Carroll, entre a que salientan a continuación en 1871 das aventuras de Alicia en A través do espello e o que Alicia atopou aló. Destacan a capacidade do autor para deseñar unha personaxe que transcende o tempo a través dun libro "no

\footnotetext{
${ }^{8}$ Obra que nos inicios da década dos oitenta comezou a traducir tamén Carlos Casares, nun proxecto persoal por seguir achegando clásicos da literatura universal, tal e como sinalan Luna Alonso e Galanes Santos (2012).
} 
que o absurdo e a violencia do mundo -e non só do País das Marabillas- exprímese cunha intensidade e unha severidade de liñas que fai parecer artificiosos a tódolos tremendismos" (Carroll 1984: 14) por iso conclúen que,

\footnotetext{
A suma lección de Alicia é, tal vez, que só ollando con curiosidade e lucidez o horror do mundo, se poden atravesa-las tebras co fachizo do humor, cantando o cantar do propio destino, e acabar ciscando polo aire da ilusión ó que pertencen as cartas do barallo que tanto sufrimento causan coa súa soberbia estupidez. (Carroll, 1984: 14)
}

A introdución aínda se completa cunhas "Notas sobre as ilustracións", onde explican con moito detalle como os deseños que acompañan o orixinal que Carroll lle regala a Alice Liddell foron feitos por el mesmo, mentres que para a publicación recorre a John Tenniel, caricaturista político. Detállanse algunhas das diatribas que sufriron os deseños e como a personaxe de Alicia é produto só da imaxinación e da man do ilustrador, non así o resto de protagonistas saídos da imaxinación de Carroll, que seguiu moi de preto o seu deseño.

Péchase a introdución cunha "Nota sobre as traducións de Alicia", na que se refiren ao celo posto por Carroll na busca de tradutores cara ao francés e ao alemán, labor complicado pola dificultade que entrañaba traducir os versos e as súas parodias, barallando a posibilidade de deixalos fóra da obra. Este recurso foi adoptado por algúns tradutores, non polos galegos, que consideran que

\footnotetext{
a obra perdía demais sen eles e fixemos por darlles voz galega, indicando en nota cal é o orixinal que parodian. Algúns deses orixinais son aínda ben populares en Inglaterra, outros xa non, así que o argumento de falla de familiaridade valería tamén moitas veces para o lector inglés de hoxe. (Carroll, 1984: 22)
}

Esta toma de posición adianta unha das características xerais desta tradución, como é a fidelidade ao orixinal e o achegamento ao polo da estranxeirización, o que non impide que no conxunto da obra en lingua galega se logre un estilo natural en canto ao léxico e rico en canto ás estruturas e elementos propios da lingua meta, en especial no desvío da estratexia dominante da estranxeirización que adoptan cos nomes dos personaxes (Lorenzo, 2015: 76-81). A isto súmase o amplísimo aparato de notas, que aparece colocado no final da obra. Nelas explican as fontes que parodia Carroll, aqueles termos pouco usuais para os galegos pola distancia cultural (significado de Mary Ann, como criada), os elementos descoñecidos na nosa cultura (bathing-machines ou máquinas de bañarse), as referencias reais das personaxes fantásticas (O Parrulo é o Reverendo Robinson Duckworth que acompañou a Carroll ao pícnic que deu orixe a Alicia) ou aqueles nos que están inspirados (a Duquesa, no cadro da Duquesa Fea, de Quintin Matsys); a explicación de fraseoloxía e ditos ingleses que aparecen implícitos no texto (“Arregaña-los dentes coma un gato de Cheshire”, 
“Tolo como un sombreireiro”)... Nestas notas tampouco falta a referencia ás primeiras traducións ás linguas do ámbito ibérico, iniciadas nos anos vinte (castelán e catalán) e á bibliografía que os tradutores manexaron tanto sobre Alicia coma sobre a biografía de Carroll.

A fortuna desta tradución de Teresa Barro e Fernando Pérez-Barreiro plásmase tanto no recoñecemento do Premio Nacional de Tradución recibido ao ano seguinte da súa publicación, como nas múltiples reedicións ${ }^{9}$ que a obra coñeceu durante décadas e nas que foron moi poucos os cambios introducidos até o ano 2002, momento no que a editorial decidiu levar a cabo unha renovación da colección "Xabarín” e integrar esta obra na serie "Xabarín de ouro”, na que manteñen o texto íntegro de Teresa Barro e Fernando Pérez-Barreiro, aínda que substitúen as ilustracións de Tenniel polas do ilustrador galego Federico Fernández Alonso, Premio Nacional de Ilustración 2002. Este cambio foi valorado positivamente pola crítica, que destacou a súa expresividade (CLIJ, 2003: 73; Nicolás, 2003: IV; Fraga, 2003: 45) ${ }^{10}$, aínda que dende o noso punto de vista lle imprimen á obra un carácter algo máis tétrico do agardado, pero concordamos con Ramos $(2010,2019)$ en que ilustrar obras clásicas é un desafío debido á ingrata posición do artista ao ter que dialogar ou silenciar unha longa tradición iconográfica. Nesta (re)actualización do texto tamén se trasladan as notas ao rodapé de cada páxina, o que facilita a súa lectura e integración co texto ao que achegan aclaracións, aumentando mesmo o número delas, como as referidas ás explicacións da orixe e fontes das que parte Carroll para os seus xogos de reescrita e subversión, as referidas a proverbios ingleses no texto...

O éxito desta primeira tradución animou á editorial a publicar un ano despois, en 1985, Do outro lado do espello e o que Alicia atopou aló, incluída na mesma colección e da man dos mesmos tradutores, polo que o proxecto gaña en unidade e mantén as mesmas premisas da anterior. Porén, malia a unidade e coherencia que isto lle imprime ás dúas obras, a fortuna de ambas é ben dispar, pois mentres a primeira foi reeditada en numerosas ocasións, a segunda está actualmente fóra do catálogo editorial e non foi incorporada a ningunha outra colección.

\section{A década dos noventa}

Houbo que agardar unha década despois destas primeiras achegas, ata 1995, para que se publicase unha nova adaptación de Alicia no País das Marabillas, nesta ocasión na colección “Os meus contos clásicos favoritos”, da editorial Sálvora, na que conta coas ilustracións de Manuel Barco. A

\footnotetext{
${ }^{9}$ Como se pode seguir por Roig, Domínguez e Mociño (2008).

${ }^{10} \mathrm{E}$ tamén destacou da obra o universo inzado de fantasía e as situacións próximas ao absurdo, ademais da irrefreábel liberdade no ámbito imaxinativo, o onirismo ou a lóxica fronte á perspectiva máis convencional do mundo, así como os continuos xogos paródicos sobre a vida escolar inglesa.
} 
edición é un conto ilustrado de gran formato e pastas duras, subvencionado pola Xunta de Galicia, no que non consta o nome do tradutor/adaptador e que se inicia cunha Alicia durmida diante dun libro que comeza a soñar e leva o lectorado polas principais escenas e personaxes da obra, nun texto moi simplificado, que cede o protagonismo a unhas ilustracións a toda páxina de carácter figurativo e moi coloristas.

Un ano despois, en 1996, publicouse Alicia para nenos [The Nursey Alice, 1890] da man do Equipo Tris Tram, que manifesta respectar ao máximo a publicación orixinal. Trátase dunha adaptación de Alicia no País das Marabillas, que realizou o propio Carroll destinada á nenez, como sinala no prólogo "dirixido a todas as nais". O texto recolle en catorce breves episodios as aventuras máis significativas de Alicia e apóiase nas ilustracións realizadas por Tenniel para a primeira versión de Alicia, de xeito que a narración constitúe unha explicación de cada un dos debuxos. Complétase cunha "Felicitación de Pascua para todos os cativos que queren a Alicia" e cunha "Felicitación de Nadal. Dunha fada a unha nena”, ambas asinadas polo autor. Desta proposta a crítica salientou a fidelidade da edición galega co orixinal de Carroll (Manteiga, 1997: III), que viña ampliar así a presenza deste clásico universal no corpus traducido á lingua galega ${ }^{11}$.

Ademais da reedición da tradución canónica de Alicia no País das Marabillas, que viu a luz, como sinalamos, nunha remozada colección "Xabarín de ouro" en 2002, tamén se editaron nestes anos dúas novas adaptacións e outras tantas traducións.

As adaptacións son versións moi simplificadas que buscan propiciar un contacto precoz da primeira infancia co universo ficcional deste clásico universal. No primeiro caso, trátase dun estoxo no que se reúnen dez contos baixo o título xenérico de Colección Xirasol, editado por Everest Galicia en 2007, con tradución de Irene Penas e ilustracións de Ada García. Entre os títulos recompilados aparece Alicia no País das Marabillas, un texto de marcado carácter didáctico, tal como revela a guía de lectura e as actividades que se atopan no final do volume. No segundo caso, é unha adaptación realizada por María Lado para Edicións do Cumio e publicada en 2010. Trátase dun álbum de gran

\footnotetext{
${ }^{11}$ Na que tamén conta cunha edición dese mesmo ano de 1996 de $A$ caza do carbairán [The hunting of the snark, 1876], da man da escritora Marilar Aleixandre para a colección “Xabarín”. Un longo poema épico en oito episodios no que Carroll conta a fabulosa aventura dunha tripulación que parte á caza do carbairán, un animal fantástico. Salienta na obra a detallada introdución, na que a tradutora clarifica aspectos como os da tradición na literatura universal da caza de animais fantásticos, a personalidade de Lewis Carroll, refírese ao contexto literario no que se insire este poema e o proceso creativo que deu lugar á composición, ademais de presentar os criterios adoptados na tradución e unha bibliografía seleccionada sobre a obra do autor inglés. A crítica salientou no momento da publicación o "inesperado e sorprendente" que resulta este poema en clave épica (Martínez Bouzas, 1996: 6) e a perspectiva adoptada pola tradutora, que "interpreta e recrea en clave enxebre o tecido léxico e interpretativo do texto", amais de que as ilustracións de Henry Holiday enriquecen un texto fermoso e intelixíbel (Bernárdez, 1996: 3).
} 
formato e a toda cor, dirixido a primeiros lectores e lectorado autónomo, con ilustracións de Ana Santiso Villar, nas que se recrea o mundo fantástico no que transcorre a historia, caracterizado por imaxes figurativas con debuxos detallados que complementan os textos.

É de sinalar nesta versión o recurso á retranca de raizame galega, no sentido de penetrar nun plano máis intelectual e emocional, como sinala Ánxela Gracián (2010: 16), a sensibilidade que transloce nas eleccións léxicas, determinadas por un criterio memorialista, na selección dos elementos principais da narración orixinal e no coidado da edición e da calidade plástica. Probabelmente esta adaptación sexa froito, como sinala a profesora Ana Margarida Ramos (2015: 93-94), de fenómenos como a estrea do filme de Tim Burton, nun agromar de novas reescritas deste clásico universal que non deixa de sorprender e desafiar a quen se achega a el, tanto dende o punto de vista lingüístico, coma literario, porque "as Alicias crean espazo e tempo para que os lectores exploren o xogo en que se transforma a lectura" (Ramos, 2015: 94).

Coincidindo coa efeméride da celebración do 150 aniversario da publicación da obra en 2015 viron a luz dúas traducións. A primeira é unha edición de El Patito Editorial, un volume en tapas duras, cun papel de alta gramaxe e coas ilustracións de Fausto Isorna, nas que recorre á colaxe fotográfica. A tradución é de Xavier Queipo a partir da edición de Alice's Adventures in Wonderland, publicada por D. Appleton and Co. New York en 1866. Sen dúbida trátase da edición máis ambiciosa de todas cantas se teñen publicado en lingua galega, fundamentalmente polo investimento e a alta calidade material e estética, que contou coa axuda da Secretaría Xeral de Cultura da Consellería de Cultura, Educación e Ordenación Universitaria da Xunta de Galicia.

Ao visualismo surrealista das composicións realizadas por Fausto Isorna súmase a limpeza do texto e a desaparición do aparato de notas, que quedan reducidas a unicamente catorce, colocadas no final do volume. Isto fai pensar na decisión editorial de ofrecer unha obra de fronteira que busca captar a atención da xuventude pero, sobre todo, dun público máis avezado e formado, coñecedor deste clásico, que agora pode achegarse á obra na lingua propia, respectuosa coa norma ortográfica vixente. A crítica, tal como se pode seguir nos Informes de literatura (2015), destaca a aparición da obra no marco de múltiples proxectos artísticos ao redor da obra de Carroll con motivo do sesquicentenario da súa publicación e chama a atención sobre a busca do lectorado adulto e incluso de lecturas en clave psicanalítica, filosófica, metafísica e mesmo feminista.

Un ano despois, en 2016, pero tamén como efecto da efeméride da publicación da obra, a editorial Lata de Sal publicou As aventuras de Alicia no País das Marabillas na colección "Vintage", destinada a libros inesquecíbeis, escritos e ilustrados en calquera lugar do mundo hai máis de trinta anos e que nunca foron publicados en lingua galega. Trátase da tradución feita por Rafa Salgueiro da 
adaptación da historia orixinal publicada en 1907, unha edición de coleccionista de moi reducido tamaño $(95 \times 122 \mathrm{~mm})$, en papel de 128 gramos e pensada para a infancia, tal como se pode ler na nota que aparece na páxina de títulos de crédito: "E no País das Marabillas todo o mundo pode entrar. Sen pasaporte”.

O volume, de capa dura e reminiscencias de libro antigo, conta cunha breve introdución na que se explica que o texto representa unha sexta parte da extensión da obra orixinal, aínda que conta con todas as personaxes e escenas deste, e que esta edición en cor e prezo popular foi posíbel grazas ás novidosas técnicas de imprenta de inicios do século XX, na que aparecen trinta e dúas ilustracións de Sir JohnTenniel. Saliéntase tamén que é a primeira e única edición na que a protagonista aparece caracterizada cun vestido vermello, dende que en 1903 aparecera a primeira edición coa característica cor azul, que foi a que permaneceu posteriormente.

Todas estas edicións, nuns casos adaptacións para o lectorado infantil, noutros traducións fieis a diferentes edicións publicadas da obra orixinal, evidencian o interese dos axentes literarios por se achegar a este clásico universal da LIX. Con elas contribuíuse a que diferentes xeracións se familiarizaran con personaxes e universos literarios referenciais, relevantes polo seu valor intrínseco de memoria colectiva, pola súa capacidade para conectar co potencial lectorado infantil e xuvenil e por representar propostas de modelos literarios con interese cara ao fomento da educación literaria. De feito, cando o mediador emprega clásicos como Alicia no País das Marabillas entre os máis novos está espertando o interese pola obra completa a partir das imaxes e escenas seleccionadas, demostra gran creatividade e recursos, evita que as lecturas realizadas sexan rutineiras e frustrantes, ademais de compartir universos ficcionais que contribúen a ler o mundo.

\section{A modo de conclusión}

Por todo o dito, o rico universo literario creado por Lewis Carroll incorporouse ao sistema literario galego no momento en que este iniciou o camiño cara á súa consolidación, aínda que a súa pegada a través de xogos intertextuais nas obras de autoras e autores galegos está presente dende os primeiros pasos desta literatura na década dos anos sesenta ${ }^{12}$. As primeiras traducións aparecen no momento en que se estaba a superar a febleza e resistencia propias dunha cultura en proceso de descolonización, que foi adquirindo cada vez máis importancia dentro do sistema literario, tanto pola incidencia no repertorio coma pola importancia de cara a unha normalización lingüística que

\footnotetext{
${ }^{12}$ Pénsese no caso do clásico galego A galiña azul (1968), de Carlos Casares, que comparte coa obra de Carroll o comezo nun espazo real e a xeración de conflitos varios por mor do azar, a rápida adaptación dos protagonistas ás novas situacións e a desaparición dos lindes entre realidade e fantasía.
} 
durante esta década foi fundamental para reivindicar o uso da lingua galega como vehículo de comunicación válido en calquera aspecto da cultura.

O resultado destas catro décadas son cinco traducións das obras que teñen a Alicia como protagonista e catro adaptacións, máis ou menos libres, para o lectorado máis novo. Unha incidencia cuantitativa que semella pouco relevante no marco da produción xeral da LIX galega, mais que probabelmente se explique polo feito de que a tradución de excelente calidade que viu a luz en 1984 deste clásico universal coartou a posibilidade de novas traducións, aínda que non de adaptacións, que son ben poucas se se ten en conta os recorrentes diálogos intertextuais que creadores e creadoras galegas manteñen con este clásico universal, así como as múltiples propostas que noutros contextos culturais teñen vido a lume, en especial as máis próximas ao universo do libro-obxecto (García Pedreira e Cortizas, 2017).

\section{Bibliografía}

\section{Bibliografía activa}

CARROLL, L. (1983). Alicia no País das Maravillas. Madrid: Susaeta (ilust. René Cordero).

CARROLL, L. (1984). As aventuras de Alicia no País das Maravillas. Vigo: Edicións Xerais de Galicia (Premio Nacional de Tradución 1985, Ministerio de Cultura, ilust. John Tenniel, introd., trad. e notas Teresa Barro e Fernando Pérez-Barreiro).

CARROLL, L. (1985). Do outro lado do espello e o que Alicia atopou aló. Vigo: Edicións Xerais de Galicia (ilust. John Tenniel, introd., trad. e notas Teresa Barro e Fernando Pérez-Barreiro).

CARROLL, L. (1995). Alicia no País das Marabillas. Santiago de Compostela: Sálvora Ediciones/Libsa (ilust. Manuel Barco, trad. e adapt. Ramón Álvarez Losada).

CARROLL, L. (1996). Alicia para nenos. Lugo:TrisTram (ilust. Tenniel, trad. Equipo TrisTram).

CARROLL, L. (1996). A caza do carbairán. Vigo: Edicións Xerais de Galicia (introd., trad. e notas $\mathrm{M}^{\mathrm{a}}$ Pilar J. Aleixandre, ilust. Henry Holiday).

CARROLL, L. (2002). As aventuras de Alicia no País das Marabillas. Vigo: Edicións Xerais de Galicia (introd., trad. e notas Teresa Barro e Fernando Pérez-Barreiro, ilust. Federico Fernández Alonso).

CARROLL, L. (2007). Colección Xirasol. A Coruña: Everest Galicia (trad. Irene Penas, ilust. Ada García).

CARroll, L. (2010). Alicia no País das Marabillas. Vilaboa-Pontevedra: Edicións do Cumio (adaptación María Lado Mariño, ilust. Ana Santiso Villar). 
CARroll, L. (2015). Aventuras de Alicia no País das Marabillas. Santiago de Compostela: El Patito Editorial (trad. Xavier Queipo, ilust. Fausto Isorna).

CARROLL, L. (2016). As aventuras de Alicia no País das Marabillas. Madrid: Lata de Sal (ilust. Sir John Tenniel, trad. Rafa Salgueiro).

\section{Bibliografía pasiva}

AGRELO-COSTAS, E. e MOCIÑO-GONZÁLEZ, I. (2010). "Contactos e intercambios da Literatura Infantil e Xuvenil galega coa catalá e vasca: diálogos dende a periferia”. En LAFARGA, F., PEGENAUTE, L. e GALlÉN, E. (eds.), Interacciones entre las literaturas ibéricas. Relaciones literarias en el ámbito hispánico: traducción, literatura y cultura (pp. 7-31). Bern: Peter Lang.

ALONSO, F. (2006). "Quince puntos para o debate sobre Literatura Infantil e tradución”. En LUNA ALONSO, A. e MONTERO KÜPPER, S. (eds.), Tradución e Política editorial de Literatura infantil e xuvenil (pp. 91-93). Vigo: Universidade de Vigo.

BENDOIRO MARIÑO, P. (2012). "Primeras traducciones de la literatura infantil y juvenil al gallego y su recepción”. En RAMOS, R. e FERNÁNDEZ MOSQUERA, A. (eds.), Literatura Infantil y Juvenil y Diversidad Cultural/Literatura para a Infância e Juventude e Diversidade Cultural (pp. 39-51). Vigo/Braga: ANILIJ/ELOS/Centro de Investigação em Estudos da Criança (Instituto de Educação - Universidade do Minho). Consultado o 29 de agosto de 2020, http://anilij.uvigo.es/wp-content/uploads/2017/04/2.pdf.

BENDOIRO MARIÑO, P. (2015). “Tradución”. En ROIG RECHOU, B.-A. (coord.), Historia da Literatura Infantil e Xuvenil galega (pp. 270-275). Vigo: Edicións Xerais de Galicia.

BECKETT, S. (2008). Crossover Fiction: Global and Historical Perspectives. New York and London: Routledge.

BERNÁRDEZ, C. L. (1996). "Lewis Carroll á caza da imaxinación”. Faro de Vigo, Faro das Letras, CXXXI, 3.

Biblioteca da Tradución Galega (BITRAGA). 1980-2020 (sen data). Consultado o 29 de agosto de 2020, http:// bibliotraducion.uvigo.es/.

CLIJ (2003). "Alicia no País das Marabillas. Lewis Carroll". Cuadernos de Literatura Infantil y Juvenil, $158,73$.

DOMÍNGUEZ PÉREZ, M. (2008a). Las traducciones de literatura infantil y juvenil en el interior de la comunidad interliteraria específica española (1940-1980) (tese de doutoramento). Santiago de Compostela: Universidade de Santiago de Compostela. http://hdl.handle.net/10347/2400

DOMÍNGUEZ PÉREZ, M. (2008b). “As primeiras traducións de literatura infantil e xuvenil ao 
galego: normas de tradución, difusión e recepción”. Boletín Galego de Literatura, 39-40, 37 60.

DOMÍNGUEZ PÉREZ, M. (2008c). Polo mar van as sardiñas y sus traducciones. Madrygal, 11, 25 33. Consultado o 15 de agosto de 2020, https://revistas.ucm.es/index.php/MADR/article/view/MADR0808110025A.

DOMÍNGUEZ PÉREZ, M. (2012a). "La Literatura Infantil y Juvenil traducida en el ámbito español”. En RAMOS, R. e FERNÁNDEZ MOSQUERA, A. (eds.), Literatura Infantil y Juvenil y Diversidad Cultural/Literatura para a Infância e Juventude e Diversidade Cultural (pp. 121-136). Vigo/Braga: ANILIJ/ELOS/Centro de Investigação em Estudos da Criança (Instituto de Educação - Universidade do Minho).

DOMÍNGUEZ PÉREZ, M. (2012b). "La Galera: La traducción gallega de versiones catalanas de cuentos populares de diversos orígenes”. En RODRÍGUEZ, B. e REIS DA SILVA, S. (eds.), Literatura Infantil y Juvenil e Identidades / Literatura para a Infância e Juventude e Identidades (pp. 113-127). Vigo/Braga: ANILIJ/ELOS/Centro de Investigação em Estudos da Criança (Instituto de Educação - Universidade do Minho).

EVEN-ZOHAR, I. (1978). Papers in Historical Poetics. Tel Aviv: Porter Intitute.

EVEN-ZOHAR, I. (1996). "A posición da traducción literaria dentro do polisistema literario". Viceversa. Revista Galega de Traducción, 2, 57-65.

EVEN-ZOHAR, I. (2008). "La fabricación del repertorio cultural y el papel de la transferencia" ["The Making of Culture Repertoire and The Role of Transfer"]. En SANZ CABRERIZO, A. (ed.), Intercultura.Transliteratura (pp. 217-226). Madrid: Arco Libros.

FERNÁNDEZ RODRÍGUEZ, Á. (2010). "La traducción en Galicia y la industria editorial (19802008)”. En GALLÉN, E., LAFARGA, F. e PEGENAUTE, L. (eds), Traducción y autotraducción en las literaturas ibéricas (pp. 93-107). Berna: Peter Lang, vol. 2.

FIGUEROA, A. (2003). “Literaturas minoritarias: autonomía e relacións interliterarias”. Anuario de Estudios Literarios Galegos, 2002, 55-67.

GALANES, I. (2010). "Panorama da literatura traducida en Galicia (1980-2008): fluxos literarios peninsulares”. En GALLÉN, E., LAFARGA, F. e PEGENAUTE, L. (eds), Traducción y autotraducción en las literaturas ibéricas (pp. 109-124). Berna: Peter Lang, vol. 2.

GALANES, I. (2014). “Carlos Casares y la traducción: obra dispersa e inédita”. Quaderns. Revista de Traducción, 21, 183-198.

GARCÍA PEDREIRA, R. e CORTIZAS VARELA, O. (2017). "As adaptacións dos clásicos da Literatura Infantil e Xuvenil en formato 'pop-up' para primeiros lectores”. En VASCONCELOS, A. C., NEIRA RODRÍGUEZ, M. e REIS DA SILVA, S. (coord.). Primeiros Livros, Primeiras Leituras/ Primeiros Libros, Primeiras lecturas (pp. 133-144). Porto: Tropelias \& 
Companhia.

GARRIDO VILARIÑO, X. M. e LUNA ALONSO, A. (1998). "O fantasma da ópera, Gaston Leroux". Viceversa. Revista Galega de Traducción, 4, 187-192.

GRACIÁN, Á. (2010). “Carroll retranqueiro”. Tempos Novos, Protexta, 14, 16.

LEMA, C. (2009). "Importación e exportación de textos literarios. Unha crítica á noción de literatura mundial como paradigma”. Grial, 182, 120-135.

LORENZO, L. (2015). "Alice in Wonderland / Alicia no país das maravillas, ese admirado clásico”. En ROIG RECHOU, B.-A., SOTO LÓPEZ, I. e NEIRA RODRÍGUEZ, M. (coords.), Retorno aos clásicos. Obras imprescindíbeis da narrativa infantil e xuvenil (pp. 71-83). Vigo: Edicións Xerais de Galicia.

LLUCH, G. (2009). Como reconocer los buenos libros para niños y jóvenes. Bogotá: Fundalectura.

LUNA ALONSO, A. (2017). "O papel da tradutora no campo literario galego". Madrygal, 20, 147 156. https://doi.org/10.5209/MADR.56228

LUNA ALONSO, A. e GALANES SANTOS, I. (2012). “As traducións inéditas de Carlos Casares”. Grial, 196, 38-47.

LUNA ALONSO, A., FERNÁNDEZ RODRÍGUEZ, A., GALANES SANTOS, I. e MONTERO KÜPPER, S. (eds.) (2015). Literaturas extranjeras y desarrollo cultural. Hacia un cambio de paradigma en la traducción literaria gallega. Berna: Peter Lang.

MANTEIGA, F. (1997). “Alicia para todos”. El Progreso, Táboa Redonda, 24, 19 abril, III.

MARTÍNEZ BOUZAS, F. (1996). “Avesío Carbairán”. O Correo Galego, Revista das Letras, 113, 20 xuño, 6.

MOCIÑO-GONZÁLEZ, I. (2010). “A renovación dos clásicos. Jules Verne na colección 'Xabarín' (agora 'Xabaril') de Xerais”. Malasartes. Cadernos de Literatura para a Infância e a Juventude, 20, 46-47.

MOCIÑO-GONZÁLEZ, I. (2015). "Literatura infantil y juvenil gallega: la importación de traducciones”. En LUNA ALONSO, A., FERNÁNDEZ RODRÍGUEZ, A., GALANES SANTOS, I. e MONTERO KÜPPER, S. (eds.), Literaturas extranjeras y desarrollo cultural. Hacia un cambio de paradigma en la traducción literaria gallega (pp. 105-126). Berna: Peter Lang.

MOCIÑO-GONZÁLEZ, I. e AGRELO COSTAS, E. (2008). "As traducións entre a literatura infantil e xuvenil galega e vasca”. Un mundo, muchas miradas / Mundu bat, begirada anitz, 1, 81 100. Consultado o 23 de agosto de 2020, https://ojs.ehu.eus/index.php/Mundo/article/view/2255. 
MONTERO KÜPPER, S. (2013). “As políticas de tradución no caso galego”. En MOSQUERA CARREGAL, X. M. (ed.), Lingua e tradución. IX Xornadas sobre lingua e usos (pp. 41-62). A Coruña: Universidade da Coruña.

NICOLÁS, R. (2003). “Alicia ou a subversión”. Faro deVigo, Faro da Cultura, 27, 23 xaneiro, IV.

RAMOS, A. M. (2010). Literatura para a Infância e Ilustração: leituras em diálogo. Porto: Tropelias\&Companhia.

RAMOS, A. M. (2015). "Inesgotábeis Alicias entre a literatura e o cinema". En MOCIÑOGONZÁLEZ, I. e ROIG RECHOU, B.-A. (coord.), Libros en galego de onte e hoxe para a nenez e a mocidade (pp. 94-95). Santiago de Compostela: Universidade de Santiago de Compostela.

RAMOS, A. M. (2019). "Reilustrar Alice: Tentativas de Escapar à Tentação da Disney”. Elos. Revista de Literatura Infantil e Xuvenil, 6, 37-52. https://doi.org/10.15304/elos.6.5723

RAMOS, A. M. e MOCIÑO-GONZÁLEZ, I. (eds.) (2011). Crítica e Investigación en Literatura Infantil y Juvenil/Crítica e Investigação em Literatura Infantil e Juvenil, Vigo/Braga: ANILIJ/Centro de Investigação em Estudos da Criança (Instituto de Educação - Universidade do Minho).

ROIG RECHOU, B.-A. (2005). "Literatura infantil e xuvenil en Galicia: dos inicios á consolidación”. En LLUCH, G. e ROIG RECHOU, B.-A. (coord.), Para entenderte mellor. As literaturas infantís e xuvenís do marco ibérico. Boletín Galego de Literatura, 32, 141-167.

ROIG RECHOU, B.-A. (2008). La Literatura Infantil y Juvenil Gallega en el siglo XXI. Seis llaves para entenderla mejor/ A Literatura Infantil e Xuvenil Galega no século XXI. Seis chaves para entendela mellor. Madrid/Santiago de Compostela: Asociación Española de Amigos del Libro Infantil y Juvenil/Xunta de Galicia.

ROIG RECHOU, B.-A. (coord.) (1995-2018). Informes de Literatura. Santiago de Compostela: Centro Ramón Piñeiro para a Investigación en Humanidades/Xunta de Galicia. Consultado o 28 de agosto de 2020, http://www.cirp.es/rec2/informes/.

ROIG RECHOU, B.-A. (coord.) (2015). Historia da Literatura Infantil e Xuvenil galega. Vigo: Edicións Xerais de Galicia.

ROIG RECHOU, B.-A., DOMÍNGUEZ PÉREZ, M. e MOCIÑO GONZÁLEZ, I. (2008). Produción da Literatura Infantil e Xuvenil en galego. Universidade de Santiago de Compostela, Consultado o 28 de agosto de 2020 , http://www.usc.es/export/sites/default/gl/proxectos/lijmi/descargas/elinea1.pdf.

SHAVIT, Z. (2003). Poética da Literatura para Crianças. Lisboa: Caminho

SOTOMAYOR SÁENZ, V. (2005). "Literatura, sociedad, educación: Las adaptaciones literarias". Revista de Educación. Número extraordinario, 217-238.

TARrío VARElA, A. (1986). "Rosalía, Curros, Pondal: literatura e colonización”. En Actas do 
Congreso Internacional de estudios sobre Rosalía de Castro e o seu tempo (pp. 395-401). Santiago de Compostela: Consello da Cultura Galega/Universidade de Santiago de Compostela, col. Cursos e congresos, $n .^{\circ} 44$, tomo III.

TOURY, G. (1995). Descriptive Translation Studies and Beyond. Amsterdam-Philadelphia: John Benjamins Publishing Company. 